\title{
Research on Reading Recommendation Service Model of Science and Engineering Colleges Based on Mobile Platform
}

\author{
Ying Hu \\ Library of Wuhan University of Technology, China
}

Keywords: mobile platform, science and engineering colleges, reading, reading recommendation, service mode

\begin{abstract}
Reading should be an activity throughout everyone's life, and science and engineering students seem to ignore the reading life they should have due to the limitations of their professional direction. Therefore, science and engineering students should clearly understand the importance of reading for personal growth, and schools should also create more effective reading conditions for science and engineering students. As a new library information service model, mobile platform reading is simpler and more popular and portable than reading computers. The arrival of the 4G/5G era has led to a rapid increase in the number of mobile Internet users, and the increasing use and depth of mobile platform users have laid a solid foundation and broad application prospects for the construction of library mobile platform reading services. With advanced mobile platform technology and its own rich professional resources and professionals, this paper recommends more open access resources and more professional and personalized services for readers to meet the readers' increasing reading needs.
\end{abstract}

\section{Introduction}

With the development of network communication technology, the mobile platform has become a new mass media. From mobile platform SMS to WAP access, mobile platform reading is gradually approaching readers. Paying attention to reading and guiding reading are not only the functions of libraries, but also the duties and obligations of library workers. With the development of digital libraries, the library service model is constantly innovating [1]. Internet-based library services are now deeply rooted in people's minds, using mobile platforms. The extension of the library service by the mobile communication platform will provide an opportunity for the innovation and development of the library business. The development of the mobile platform reading service will also open up a new world for the library's reading service.

\section{Characteristics of science and engineering students reading}

After entering the university, science and engineering students seem to bid farewell to the reading of literary works, and replaced them with their professional titles. The main reasons for this phenomenon are as follows [1, 2]:

1) The pressure of professional study. Many science and engineering students have a lot of learning pressure and do not have time to read the extracurricular bibliography.

2) The impact of the learning environment. In science and engineering, students in science and engineering have abandoned the exchange of extracurricular books, and they rarely talk about their professional studies.

3) The utilitarian purpose of reading. Many college students pay too much attention to the immediate interests of reading, while ignoring the refinement of personal accomplishments in those classic works. In view of the above reasons, science and engineering students limit their study to their own professional fields and some newspapers and magazines, while classic works are rarely involved. 


\section{The basic theory of mobile platform recommended reading}

\subsection{The generation and characteristics of recommended reading on mobile platforms.}

With the development of mobile communication technology and mobile Internet, digital information services such as mobile platform short message, multimedia information, and mobile platform wireless Internet access have rapidly spread [2]. The combination of mobile platform and Internet has made it a new mass media and become the future. The mainstream approach to learning models. Through the mobile platform, people can not only realize voice communication, but also access the Internet, listen to music, play games, read news, send and receive emails, order goods, and so on.

The mobile platform recommends reading as a mobile platform as a terminal, accessing, receiving, and downloading required information through a mobile communication network, and browsing and watching (listening) reading activities on the mobile platform. As a reading carrier, the mobile platform has many unique features, such as portable, fragmented, and proactive, in addition to the characteristics of fast speed, large amount of information, and rich content. The portable nature of the mobile platform allows users to access or receive a variety of news information anytime, anywhere, anytime, anywhere [2]. At the same time, the mobile platform can be used as a reading tool to fill a lot of leisure time, such as during a trip, waiting for a car, etc., during class breaks. The initiative of mobile platform reading is mainly reflected in the search and content customization functions of mobile platform reading software. Through software, readers can no longer passively accept information, improve reading efficiency and save readers' time.

\subsection{Mobile platform recommended reading form.}

At present, there are roughly three main forms of mobile platform reading, namely, mobile platform newspapers, e-books, and mobile platform magazines. Western scholars have predicted that newspapers will die by around 2030. In the face of the rise of new media, the traditional newspaper industry is in jeopardy [3]. Therefore, traditional media have established a marriage relationship with the Internet and mobile Internet, and the development of mobile phones suitable for mobile platform reading while distributing paper newspapers. Platform news and other content. Mobile platform reading is the fastest growing in the e-book market. The concept of the Internet mobile platform accelerates the popularization and application of intelligent mobile platforms, and establishes a better development environment for mobile platform reading. Since e-book prices are much cheaper than paper books, more and more readers are turning their attention from paper books to e-books [3]. The development of mobile platform magazines can be said to be a major feature of mobile platform reading. Clear reading experience, low prices are in line with the needs of readers. At present, there are three major categories of mobile platform magazine products in China: the first category is the mobile platform version of traditional paper media or Internet media; the second category is the mobile platform magazine that designs and manufactures products. The third category is the mobile platform magazine issued within the group.

\section{The necessity of developing the recommended reading service for mobile platforms in university libraries}

\subsection{Mobile platform recommended reading service features.}

1) Personalized learning theory. Personalized learning refers to learners can independently develop learning plans, select learning content, determine learning time and learning style of learning places. Personalized learning is based on the theory of multiple intelligence and metacognition. Multi-cognitive theory holds that people's intelligence is diversified, and individual differences between learners are huge. Therefore, teachers should understand and respect the differences between individuals. Metacognitive theory believes that each learner has a unique cognitive style and cognitive style [3]. Therefore, teachers should provide diverse learning resources to meet different cognitive needs. Personalized learning has the multi-dimensionality of learning resources, the 
multiplicity of learning value pursuit, the uniqueness of learning style, the lifelong nature of learning process and the autonomy, cooperation and inquiry characteristics of learning methods [1]. 2) Personalized recommendation. Personalized recommendation refers to exploiting the user's past choices or similarity relationships to explore potential users' interest objects, and filtering the information to provide users with products that meet individual needs. The personalized recommendation system usually consists of three parts: a user behavior record module, a user preference module, and a recommendation algorithm module [4]. The recommendation algorithms mainly include content-based recommendation, collaborative filtering recommendation, network structure-based recommendation, knowledge-based recommendation, and mixed recommendation.

\subsection{Analysis on the necessity of developing the reading recommendation service of mobile platform in university libraries.}

1) Meeting the needs of contemporary readers. The development of the reading service of the mobile platform of the science and engineering university library enables the readers not only to obtain basic service projects in real time, but also to enjoy the inquiry of library online resources, reference consultation and other service projects to realize the library. Online, real-time reading of books, journals, electronic documents and other information [4]. The university library of science and engineering combines advanced communication technology with library service by developing mobile platform reading service, innovates the mode of library information transmission, improves the utilization rate of library collection documents, and facilitates readers to use and obtain various information resources. Therefore, the development of the mobile platform reading service of the science and engineering university library will greatly meet the needs of the readers. 2) Improve the social value of the libraries of science and engineering universities. The mobile platform reading service is to provide readers with personalized services to customize the information or services they are interested in through the mobile platform according to their own needs. It condenses the functions of the real science and engineering university library, saves the time of the users of the science and engineering university library, revitalizes the assets of the science and engineering university library, and simplifies the library borrowing procedures and hardware equipment investment [4]. It can be said that the mobile platform reading service is the best embodiment of the library extension service. Through the development of mobile platform reading services, science and engineering university libraries can enhance their service level and public service value, and improve the social value and status of science and engineering university libraries.

\section{Design of mobile reading recommendation service platform for universities of science and engineering}

The mobile science and engineering college learning platform is designed to meet the learner's individualized learning needs. Therefore, it is necessary to first analyze the user's characteristics and user preferences and the similar relationship between users. Second, we must analyze the learning resources, including the types, characteristics, and attributes of the resources. Based on this, we use hybrid recommendations to provide learners with the learning materials they need.

\subsection{Overall structure of the platform.}

The personalized mobile science and engineering college learning platform is mainly composed of two parts: server and mobile terminal. The server side includes a web server and a database server. The database server is used to store user information and learning resources, and the web server is used to upload resources and modify the database. A mobile terminal refers to a device such as a smart phone or a tablet computer that accesses the Internet and can request a learning request or receive resources from a web server [5]. The personalized mobile science and engineering college learning platform architecture is divided into three layers: data layer, business layer and presentation layer. The details are as shown in Fig.1.

The data layer collects and stores the basic information and learning behavior information of the learner and the learning resource information, and provides information for the business layer 
through pre-processing. The business layer is the core layer of the whole platform. Through data mining and data analysis, the information transmitted from the data layer is filtered, analyzed, processed and modeled to establish a user preference model [5]. The application layer accepts the user preference model and recommends personalized learning content for learners.

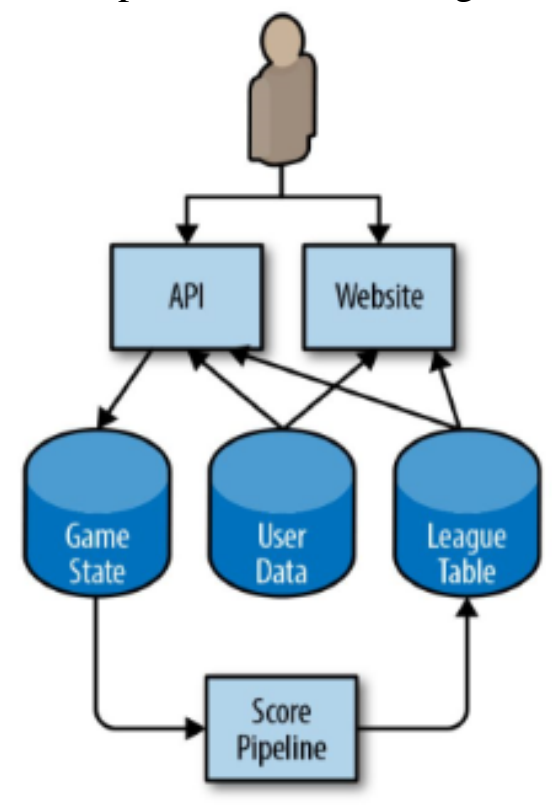

Fig. 1 Recommended reading platform structure layer

\subsection{User preferences module.}

To establish a user preference model, first collect and organize user information. User information includes basic information and learning behavior information. The basic information refers to the personal information that the user fills in when registering [6]. The learning behavior information is information collected through various learning behaviors of the user, such as click, browse, search, download, collect, share, and evaluate behavior data. The server side analyzes and models the user information. A simple decision tree algorithm can be used for simple processing of new user basic information [5]. The algorithm does not need to understand the user's background knowledge, and only needs to classify the user to initially predict the user's attitude towards the learning material. For example, children may be interested in children's songs in science and engineering colleges, and high school students may be interested in grammar knowledge. To use the decision tree for data classification, a set of training data sets is first used to train the classifier, and then the real user data is classified by the built classifier. After the basic information of the user is simply processed, the user preference model is established by analyzing the learning behavior data of the user [6]. The specific method is to use keywords and corresponding weights to express preferences. There are various methods for calculating keyword weights, and the TF-IDF (word frequency-inverse document frequency) algorithm is simple and easy to implement.

\subsection{Learning resource analysis module.}

Listening, speaking, reading, writing and translating are the basic skills of science and engineering colleges. Among them, speaking and writing are output skills, listening and reading are input skills, and translation is the basis for various skills. Providing personalized recommendations for students, mainly recommending input language materials, namely listening materials and reading materials, and in order to improve writing skills, teachers can also provide students with essays. Before providing students with reading materials and essay writing, teachers must first understand the difficulty of vocabulary in materials [7]. The difficulty of vocabulary depends on the length of the vocabulary, the number of syllables, and how often. 


\subsection{Personalized recommendation module.}

Due to the limited data storage and processing capabilities of the mobile terminal, the personalized recommendation module of the platform is implemented on the server side. The recommendation algorithm selects a content-based recommendation algorithm. The algorithm establishes a configuration file for the user and the learning data respectively, analyzes the content browsed by the user, establishes the user's configuration file, and compares the similarity between the user and the learning data to recommend the learning material that matches the user. Content-based recommendations can handle cold-start problems, and the learning materials of this platform are mostly text materials [7]. The multimedia materials are identified and easily recognized and processed by computers. Therefore, content-based recommendation algorithms are more suitable.

\section{Summary}

Based on the current digital environment, with the emergence of multi-channel, convenience, information explosion and information pollution of digital information, more and more mobile platform users require science and engineering university libraries to provide deeper humanization. Mobile platform reading consulting services. As a representative of humanized mobile platform reading service, information consulting service is a high-level library service work. It takes information resources as the working object, uses information development as a means, and combines the information needs of specific users to analyze and synthesize information. Concentrate, refine, and develop into value-added or new information products to meet the readers' needs for humanized services in science and engineering college libraries.

When developing the mobile platform reading service, the science and engineering university library can establish a mobile platform reading service mode that meets the needs of college students according to the technical conditions of the mobile communication network and the functions of the mobile platform terminal, taking into account various service methods. It is believed that in the near future, the mobile platform reading service of science and engineering university libraries will be more and more perfect. Through the mobile platform reading service, the science and engineering university library will be getting closer and closer to the readers, and the library will be put into the library. Pockets will no longer be dreams.

\section{References}

[1] H.L. Liu, Research Status and Trends of China's Domestic Mobile Library, National Library Journal, 2012, vol.2, pp.15-18.

[2] X.Y. Yan, Research on the current status of mobile information services in domestic libraries, Library Science Research, 2010, vol.2, pp.63-67.

[3] C.T. Li, SOA-based university library information service platform design, computer CD software and application, 2014 , vol.10, pp.21-23.

[4] G.Y. Li and Y.J. Jiang, Theoretical Construction and Characteristic Analysis of Personalized Learning, Journal of Northeast Normal University, 2005, , vol.3, pp.152-154.

[5] Y.W. Liu, RSS set off a revolution in mobile phone reading, China New Communications, 2016, vol.6, pp.79-80.

[6] Sh.H. Ning, Research on RSS Push Service in University Libraries, Library Science Research, 2017, vol.10, pp.83-85.

[7] W.Y. Ge and Y.R. Ye, Design and Implementation of Personalized Recommendation Module for Reading System Based on Topic Model, Technology and Industry, 2013, vol.6, pp.151-155. 